\title{
IMPACTOS TRIBUTÁRIOS DOS MÉTODOS DE CÁLCULO DE PREÇOS DE TRANSFERÊNCIA EM OPERAÇÕES DE IMPORTAÇÃO
}

\author{
Mônica Gisele Brancher Pedó \\ monicapedo@terra.com.br \\ Universidade Federal do Rio Grande do Sul - RS / Brasil \\ Cláudio José Müller \\ cmuller@producao.ufrgs.br \\ Universidade Federal do Rio Grande do Sul - RS / Brasil \\ Marcelo Nogueira Cortimiglia \\ marcelo.cortimiglia@mail.polimi.it \\ Politecnico di Milano - Milão / Itália
}

Recebido em 27/05/2008

Aprovado em 12/05/2010

Disponibilizado em 01/04/2011

Avaliado pelo sistema double blind review

Revista Eletrônica de Administração

Editor: Luís Felipe Nascimento

ISSN 1413-2311 (versão on-line)

Editada pela Escola de Administração da Universidade Federal do Rio Grande do Sul.

Periodicidade: Quadrimestral

Sistema requerido: Adobe Acrobat Reader.

\section{Introdução}

No passado, as operações praticadas pelas empresas geralmente eram simples, envolvendo apenas unidades estabelecidas em locais próximos. Mesmo quando as transações eram efetuadas entre empresas separadas por grandes distâncias, em geral tratava-se de empresas distintas e os registros contábeis e tributários não diferiam daqueles efetuados em operações de compra e venda com clientes estabelecidos no mesmo município, estado ou país (BOMFIM; PASSARELLI, 2006). Com a intensificação do desenvolvimento comercial e industrial, porém, as organizações passaram a especializar o trabalho e a mudar do sistema doméstico para operações mais complexas, envolvendo maior número de fornecedores e clientes.

Entre as mudanças, está o repasse de atividades que não são o objetivo principal da empresa para terceiros ou outros ramos do grupo organizacional. Com a descentralização, as organizações podem optar por estabelecer filiais ou novas empresas do grupo (empresas REAd - Edição 68, Volume 17, Nº 1, jan/abr 2011 - p. 270-297 
ligadas) em locais mais próximos de fornecedores estrategicamente importantes ou de seu mercado de atuação, além de terem a oportunidade de procurar locais que ofereçam vantagens como mão-de-obra mais barata e/ou mais especializada, bem como incentivos fiscais ou alíquotas reduzidas (FERNANDES, 2007; JOHRI; PETISON, 2008). Outra tendência observada foi a ampliação dos ramos de atuação. Entre as alternativas possíveis, inclui-se a oferta de diversos produtos e/ou serviços dentro de um mesmo ramo de atuação e o estabelecimento de unidades que forneçam serviços ou insumos para outras unidades ou empresas do grupo econômico.

A diversificação é uma maneira de aumentar a probabilidade de sucesso da empresa (pela diversificação do risco) e de ampliar a atuação dentro de um ou mais mercados. De acordo com Porter (1996) e Mangueron (2003), atuar em vários segmentos de negócio é uma válida abordagem estratégica quando possibilita à empresa ser flexível e ágil para responder às flutuações de mercado e às inovações dos concorrentes. Havendo conhecimento e recursos para investir, a segmentação da empresa ou grupo econômico pode otimizar a alocação de estruturas administrativas e produtivas e de recursos para investimentos, além de ampliar possibilidades de manutenção ou obtenção de posição estratégica de mercado. Por essa lógica, as empresas passaram a comercializar seus produtos e até a instalar subsidiárias em outros países (BOMFIM; PASSARELLI, 2006).

A diversificação pode ser verificada atualmente em grandes grupos empresariais que crescem com a criação e/ou compra de empresas de menor porte e de diferentes ramos de atuação ou até mesmo com a compra de concorrentes de expressiva relevância. É dessa forma que nascem grupos empresariais de grande porte e que dominam o mercado em pouco tempo. Em muitos casos, esses grupos adquirem empresas responsáveis pela fabricação de insumos utilizados por algumas de suas fábricas, reduzindo os seus custos produtivos e tendo maior flexibilidade no que tange aos prazos de entrega e à customização dos insumos.

A tributação incidente sobre as operações, por outro lado, representa um relevante redutor de rentabilidade. Desta forma, as empresas buscam otimizar suas operações de forma que resultem no menor dispêndio possível com tributos, desde que isso não implique infringir regras tributárias (CARTER et al., 1998). A instituição de unidades em jurisdições fiscais (locais onde a administração pública tem autorização legal para legislar sobre tributos) que 
ofereçam incentivos fiscais ou que estabeleçam alíquotas reduzidas em comparação com as demais é uma das maneiras de reduzir tais dispêndios.

Ao efetuarem transações intercompanhia (ou seja, entre duas unidades do mesmo grupo econômico), as empresas estabelecem preços de transferência para os bens, produtos e serviços. O estabelecimento desses preços de transferência está diretamente ligado aos resultados obtidos nas operações e aos tributos consequentemente resultantes. Assim, as administrações fiscais estabelecem legislações específicas para evitar que e manipulação de preços de transferência implique em evasão tributária, entendida como a manipulação das operações de forma que resultem em menor tributação dentro de uma jurisdição fiscal.

Entende-se que quando duas empresas vinculadas transacionam, estas possam estabelecer seus preços de transferência de acordo com os interesses do grupo econômico, não de cada unidade, diferentemente do que ocorreria se a operação fosse efetuada entre duas empresas independentes. Isso significa dizer que os preços de transferência em operações entre vinculadas não seguiria os padrões de mercado. Como exemplo de redução de tributos por conta de preços de transferência, pode-se citar: (a) subfaturamento nas exportações, que implica em menor receita de venda declarada (logo, em menores resultados para a empresa), o que por sua vez gera uma base de cálculo menor do que em operações com empresas independentes e, consequentemente, menor incidência de tributos; e (b) superfaturamento em operações de importação, que gera custos de mercadorias e/ou custos produtivos maiores do que os que seriam apurados se as operações fossem efetuadas entre empresas não ligadas, e implica, também, em resultados menores e tributos incidentes reduzidos.

Ambas as situações, quando ocorrem em operações entre empresas estabelecidas em jurisdições fiscais distintas, são prejudiciais para a administração pública, visto que os tributos são a principal fonte de recursos do Estado (ALEXANDRINO; PAULO, 2005). Para evitar a redução de receitas tributárias decorrentes da manipulação de preços de transferência por parte das empresas, também conhecida como evasão tributária, as autoridades fiscais de cada jurisdição estabelecem legislações que limitam os preços de transferência aos preços de mercado (CARTER et al., 1998).

O aumento dos controles sobre as operações internacionais é facilmente verificável pelo aumento da frequência das auditorias fiscais relacionadas aos preços de transferência. Já em 1997, Borkowski (1997) descrevia o interesse e a preocupação demonstrados por 47 países 
com as questões de tributação relacionada com preços de transferência. Recente pesquisa efetuada pela empresa de consultoria estratégica Ernst \& Young (2009) também afirma que no período de três anos houve um crescimento relevante do número de países com legislações sobre preços de transferência (mais de 10), assim como muitos criaram fortes penalidades para aqueles que desrespeitassem as regras impostas. A mesma pesquisa também informa que os países estão aumentando o número de especialistas na área a fim de aumentar suas arrecadações, o que indica a premente importância da problemática abordada pelo presente artigo.

De fato, em 2006, de acordo com Mattei e Wulfkuhler (2006), aproximadamente quarenta países já adotavam legislações específicas a este assunto ou estavam adaptando a legislação vigente para abrangê-lo. De acordo com Neighbour (2002), mais de 60\% das operações de compra e venda ocorrem entre partes relacionadas das organizações multinacionais, o que mostra a importância das regras referentes aos preços de transferência. A relevância desse tipo de operação também é comentada por Mehafdi (2000), o qual afirma que, embora não haja um levantamento preciso sobre o assunto, acredita-se que bilhões de dólares são perdidos em arrecadação devido às fraudes contábeis em transações intercompanhia. Evidência específica de preços de transferência artificiais em atividades comerciais entre Brasil e Estados Unidos é apresentada por Zdanowicz et al. (1999). Finalmente, de acordo com Wrappe et al. (1999), os preços de transferência são responsáveis por até $30 \%$ de todos os ajustes tributários feitos pelas corporações americanas todos os anos.

No caso específico do Brasil, a Secretaria da Receita Federal do Brasil (SRFB) possui um departamento especializado em Impostos, que inclui um time de especialistas responsáveis por todas as revisões de preços de transferência. Há expectativa de que esse número aumente nos próximos anos (ERNST \& YOUNG, 2009).

A observação das regras referentes aos preços de transferência e a prévia avaliação das operações a elas sujeitas, portanto, mostra-se essencial para as empresas, sobretudo no contexto de otimização do planejamento de cadeias de suprimentos. A correta aplicação das regras legais evita que as atividades da empresa sejam erroneamente tributadas e reduz o risco de contingência para os casos de eventuais fiscalizações. A não observação da legislação propicia a ocorrência de ajustes inesperados e relevantes às bases de cálculo de tributos regrados pela legislação citada, com o consequente incremento da carga tributária efetiva no 
negócio, aumento dos custos de produção e redução da rentabilidade do negócio. A importância do tema é evidenciada pela atenção dedicada no exterior por acadêmicos e profissionais (AL-ERYANI et al., 1990; BERNARD et al., 2006; BUCKLEY; HUGHES, 2001; CHAN; CHOW, 1997; OYELERE; TURNER, 2000). Porém, estudos desta natureza relativos ao cenário brasileiro são escassos.

Neste contexto, o objetivo principal do presente estudo é a identificação dos possíveis impactos resultantes de limitações impostas pela legislação brasileira que trata sobre preços de transferência. Em particular, a pesquisa é focada nas operações de importação de bens aplicados à produção. A pesquisa, de caráter exploratória e descritiva, é ilustrada através de um estudo de caso realizado em uma empresa multinacional do ramo agrícola que efetua importação de insumos fabricados por outras unidades de seu grupo estabelecidas fora do país. O estudo foi efetuado considerando a totalidade das operações da empresa durante o período avaliado. A empresa produz em diversos tipos de implementos agrícolas, que são vendidos no Brasil e no exterior, e utiliza insumos nacionais (comprados de empresas não pertencentes ao grupo econômico) e importados (mais de 50\% são comprados de empresas do mesmo grupo econômico).

Dada a existência de dispositivos legais de diferentes alçadas que regulam o procedimento de cálculo dos preços de transferência de modo divergente (e das variadas interpretações de tais dispositivos), o objetivo deste trabalho é ilustrar comparativamente a aplicação das metodologias de cálculo previstas em lei em um caso real e discutir os potenciais impactos para a empresa derivantes de tais aplicações. Para tanto, são consideradas não somente as regras legais vigentes, mas também aquelas já revogadas que, todavia, são ainda consideradas por tributaristas como mais corretas do que as atualmente vigentes e que são objeto de discussões judiciais (BECKER; NOVASKI, 2008; DUARTE, 2005).

O artigo é estruturado da seguinte forma: na seção 2, comenta-se o entendimento da Organização para a Cooperação e Desenvolvimento Econômico (OCDE) sobre o tema e a legislação brasileira que rege os preços de transferência. $\mathrm{Na}$ seção 3, são apresentados a contextualização do estudo de caso e os procedimentos de pesquisa. $\mathrm{Na}$ seção 4 , são descritos os resultados do estudo de caso, os quais são analisados e discutidos na seção 5. Finalmente, na seção 6 são apresentadas as conclusões e propostas sugestões para trabalhos futuros.

REAd - Edição 68, Volume 17, No 1, jan/abr 2011 - p. 270-297 


\section{Preços de Transferência}

Nesta seção, são apresentados os principais tópicos que contextualizam o assunto e que possibilitam o entendimento tanto dos objetivos da legislação quanto da maneira como os cálculos de preços de transferência devem ser efetuados, bem como os ajustes necessários às bases de cálculo de tributos que eventualmente sejam necessários.

\subsection{Preços de Transferência em Operações Intercompanhia}

O preço de transferência é o preço definido para operações intercompanhia (entre empresas vinculadas) e é muito comum para empresas com vários segmentos que efetuam transações internas. Os objetivos do preço de transferência são ajudar a administração a mensurar o desempenho econômico de cada centro de responsabilidade e auxiliar no gerenciamento da sua operação (SANTOS, 2005).

Barreto (2001) entende que preço de transferência é aquele pactuado entre partes vinculadas, em transações de cunho internacional. Seguindo a mesma lógica, Fernandes (2007) define que o preço de transferência é aquele determinado para ser usado entre empresas relacionadas, particularmente pelas companhias multinacionais, relativamente a transações entre vários membros do grupo. Segundo o autor, esses preços podem ser eventualmente diferentes daqueles determinados pelas forças livres de mercado nas negociações entre partes não relacionadas. Para Wrappe et al. (1999), preço de transferência é o preço através do qual uma empresa transfere bens, serviços ou direitos para outra do mesmo grupo econômico em outro país.

Assim, o termo preço de transferência significa cotejar os preços dos bens, em operações entre partes vinculadas, com preços que são pactuados entre as partes, de forma que o grupo empresarial tenha melhoria de resultados conjuntos, mesmo que uma das partes, quando analisada individualmente, seja prejudicada. A diferença entre operações efetuadas entre empresas vinculadas e aquelas entre empresas independentes é que as empresas vinculadas podem planejar os preços de transferência de forma a tornar a sua operação vantajosa para o grupo, enquanto que se as empresas não possuem vínculo tendem a negociar os preços de forma a obter o maior resultado individual possível.

Baldenius et al. (2004) argumentam que o melhor preço de transferência seria aquele sujeito à menor incidência possível de tributos corporativos e que produzisse o melhor balanceamento do conflito entre a menor incidência de tributo e a melhor alocação de resultados/recursos. REAd - Edição 68, Volume 17, No 1, jan/abr 2011 - p. 270-297 
Para os autores, as empresas utilizam preços semelhantes entre operações internas e externas, mas aplicam descontos para operações intercompanhia, pois não precisam considerar o risco de não recebimento.

Para evitar que a manipulação de preços de transferência entre empresas vinculadas afete negativamente os tributos arrecadados, os países estabelecem legislações específicas que regulam a sua determinação. Essas legislações estabelecem metodologias de cálculo que tem o objetivo de determinar os preços que seriam praticados em operações entre não vinculadas, ou seja, objetivam calcular qual seria o preço justo, de mercado, para tais operações.

\subsection{Tributos Sujeitos à Legislação de Preços de Transferência no Brasil e o Entendimento da OCDE}

O tributo é uma obrigação imposta às pessoas físicas e jurídicas de recolher valores ao Estado, mesmo em situações em que não haja contraprestação de serviços por parte deste ao contribuinte. $\mathrm{O}$ presente trabalho trata apenas de tributos incidentes sobre a renda e que estão sujeitos aos ajustes determinados na legislação dos preços de transferência, que, de acordo com a legislação vigente, são o Imposto sobre a Renda para Pessoa Jurídica (IRPJ) e a Contribuição Social sobre o Lucro Líquido (CSLL).

Outros países possuem tributos que incidem sobre a renda. Sempre que ocorrem operações internacionais de transferência de bens entre empresas situadas em países distintos, esses tributos podem ser reduzidos em qualquer desses países através da manipulação de preços de transferência. A Organização para a Cooperação e Desenvolvimento Econômico ${ }^{1}$ (OCDE) trata sobre esta questão e sugere metodologias para impedir que isso ocorra, as quais servem de modelo para os países que possuem legislações sobre o assunto.

O Brasil não é associado à OCDE, mas baseou-se nas suas recomendações ao criar a legislação sobre preços de transferência. A entidade publicou as ditas recomendações entre 1995 e 1998, estabelecendo uma lista de princípios a serem seguidos, ao invés de ditar regras para aplicação direta (ERNST \& YOUNG, 2009). Ao estabelecer suas recomendações

\footnotetext{
${ }^{1}$ A OCDE surgiu em 1961, tendo como signatários os países mais desenvolvidos à época, com o objetivo de unir esforços para a expansão do comércio e dos investimentos internacionais entre os seus membros. Atualmente, é uma das maiores e mais respeitadas fontes internacionais de pesquisas e comparações de dados estatísticos, econômicos e sociais. Tem como objetivos monitorar, analisar e prever o desenvolvimento econômico e social de seus países membros, levando em consideração o meio-ambiente, agricultura, tecnologia, tributos e outros, a fim de propiciar desenvolvimento econômico e social dos seus membros, para alcance da estabilidade econômica e redução da pobreza dos seus povos (OECD, 2008, 2009).
}

REAd - Edição 68, Volume 17, No 1, jan/abr 2011 - p. 270-297 
relativas aos Preços de Transferência, a entidade leva em consideração o Princípio do Preço Justo (Arm's Length Principle) como norteador das mesmas. Tal princípio consiste em tratar os membros de um grupo multinacional como se atuassem como entidades separadas. Isso significa analisar e avaliar os preços de transferência praticados pelas multinacionais de acordo com o que seria praticado entre empresas independentes, seguindo as forças de mercado. Isso permite que empresas vinculadas e não vinculadas sejam tratadas de maneira igualitária, evitando possíveis vantagens tributárias decorrentes da concentração de poder econômico em grupos de empresas com ampla atuação e disponibilidade de recursos (OECD, 2009; SCHOUERI, 1999). Apesar de críticas sobre sua artificialidade e incompatibilidade com a realidade de negócios globalizados (BREM; TUCHA, 2005; SADIQ, 2004), o Princípio do Preço Justo é amplamente aceito como base da legislação sobre tributação e Preços de Transferência.

A partir do estabelecimento de metodologias de cálculo daqueles que seriam os preços praticados pelo mercado, são identificadas as bases de cálculo resultantes, que são comparadas com aquelas declaradas pelas empresas. Sendo a base de cálculo de tributos calculada pelas metodologias propostas maior do que a declarada pela empresa deve-se efetuar um ajuste fiscal da base de cálculo, o que provoca o correto pagamento de tributos por parte da empresa. Essa sistemática é adotada por todas as legislações e estudos que tratam sobre o tema.

Para evitar ajustes relevantes e inesperados, é essencial que as empresas observem a legislação vigente nos países envolvidos e que documentem todas as bases utilizadas nos cálculos de preços e de tributos pagos. Sem uma documentação concisa, a empresa fica exposta ao risco de não conseguir suportar, perante as autoridades, as suas decisões referentes aos preços de transferência, o que pode provocar a exigência de ajustes, e, eventualmente, multas e juros incidentes. Para grandes corporações, especialistas em preços de transferência sugerem que seja estabelecido um grupo de funcionários com amplo conhecimento em preços de transferência, a fim de avaliar as atividades de maneira global. Esse grupo teria como função manter-se informado sobre as regras de cada país em que a organização possui unidades e efetua transações sujeitas às legislações de preços de transferência e garantir que as regras de cada jurisdição fiscal não estejam sendo infringidas. Da mesma forma, o grupo atuaria em estudos de otimização das operações, sugerindo as transações mais vantajosas para a corporação levando em consideração as diferentes legislações incidentes. Embora seja um REAd - Edição 68, Volume 17, No 1, jan/abr 2011 - p. 270-297 
investimento alto inicialmente, pode resultar em significativa economia para empresas de grande porte que efetuem operações vultosas. Esse acompanhamento poderia, inclusive, possibilitar mudanças nas políticas de preços durante o período fiscal, a fim de evitar ajustes relevantes no fim do mesmo (MATTEI; WULFKUHLER, 2006). Outra tarefa possível para esse grupo de especialistas é criar uma estratégia corporativa para a cadeia de suprimentos, incluindo não somente os preços de transferência e a observação das suas regras em cada país, como também considerando custos de transporte e armazenamento, de forma a reduzir os custos corporativos (OUENNICHE; VILLEGAS, 2008.)

É essencial considerar que o fato de haver vínculo entre duas empresas que efetuam negociações não é pressuposto para que as transações efetuadas em conjunto sejam planejadas para obter favorecimento tributário. A valoração a preço de mercado serve para que essa confusão seja evitada, conforme as metodologias de cálculo propostas pela OCDE. Os métodos de cálculo propostos pela OCDE, de acordo com Barreto (2001) e Feinschreiber e Kent (2001) são:

(a) Método de comparação dos preços não controlados: com base na comparação dos preços praticados em operações entre partes relacionadas com preços praticados em operações normais, observadas as mesmas condições negociais. Barreto (2001) entende que esse é o método mais apropriado, por aplicar mais eficientemente o princípio do não favoritismo, mas afirma que é complicado de ser aplicado pelas diversidades encontradas entre as operações e a dificuldade de implantar os devidos ajustes;

(b) Método do preço de revenda: é aplicável às operações com revendedores, sem agregação de valor. A partir do preço de revenda a uma parte vinculada, retira-se uma margem bruta para cobrir as despesas operacionais e outras necessárias, restando um lucro compatível com seu risco e investimento. O valor líquido obtido é o considerado sem interferência. O maior problema do método é a definição da margem aplicável ao preço de revenda;

(c) Método de custo mais lucro: o preço comparável é definido pela adição de uma margem de lucro apropriada ao custo de produção. Também usa como base margens de lucro praticadas entre partes não relacionadas, mas tem como complicador o fato de que as empresas concorrentes não fornecem suas informações de custos para que a empresa possa gerar as bases de comparação;

REAd - Edição 68, Volume 17, No 1, jan/abr 2011 - p. 270-297 
(d) Quarto método: quando os três anteriores não são aplicáveis, faz-se necessário encontrar uma quarta metodologia de apuração do preço sem interferência, o que pode variar de acordo com a situação.

Os métodos descritos são sugeridos pela OCDE, mas os países podem estabelecer regras distintas. A legislação brasileira aborda o tema de modo diferente da OCDE (FEINSCHREIBER; KENT, 2001). No Brasil, a primeira lei referente a Preços de Transferência foi a Lei 9.430/96 (BRASIL, 1996), que também objetiva evitar o desvio irregular de receitas para o exterior, com consequente redução da base de cálculo dos tributos incidentes sobre os lucros das empresas brasileiras (BARRETO, 2001).

No Brasil, as leis podem estabelecer a instituição, extinção, majoração e redução de tributos, bem como definição de fato gerador e alíquotas (ALEXANDRINO; PAULO, 2005), sendo o seu detalhamento feito através de instruções normativas. A Instrução normativa da Secretaria da Receita Federal no 243/02 (IN SRF 243/02) trata especificamente sobre os preços de transferência no Brasil (BRASIL, 2002) e determina como os métodos relacionados na Lei 9.430/96 devem ser aplicados, além de identificar as situações que caracterizam vínculo societário. Dentre as metodologias de cálculo apresentadas e as especificidades de cada situação, o contribuinte poderá aplicar o método que lhe for mais vantajoso, ou seja, seguindo as determinações da IN, poderá optar pelo cálculo que proporcionar maior preço parâmetro para as suas atividades, o qual será comparado com os preços constantes dos documentos de aquisição (BRASIL, 1996, 2002).

Para fins de cálculo do custo total de aquisição a ser considerado, à exceção do método Custo de Produção menos Lucro, deve-se considerar como preço de aquisição o valor do produto, as despesas de transporte e o seguro, quando suportados pelo importador, e os tributos não recuperáveis devidos na importação. Ao considerar os gastos com frete e transporte como integrantes do preço de compra, para fins de comparação, é necessário que os mesmos sejam considerados também no preço de venda.

Para chegar ao preço parâmetro, os preços apurados dos insumos são multiplicados pelas quantidades relativas à respectiva operação e os resultados são somados e divididos pela quantidade total. Dessa forma, encontra-se o preço médio ponderado a ser comparado com aquele registrado nos custos de produção.

REAd - Edição 68, Volume 17, No 1, jan/abr 2011 - p. 270-297 
Se o preço praticado na aquisição dos bens for superior ao preço parâmetro, o valor resultante de excesso de custos, despesas e encargos, considerado indedutível na determinação da base de cálculo de tributos deverá ser a base de ajuste a ser efetuado pelo contribuinte. As metodologias propostas pela legislação brasileira para calcular os preços parâmetro (preços máximos aceitos como dedutíveis) em operações de importação de bens a serem aplicados em processos produtivos são as que seguem:

(a) Método dos Preços Independentes Comparados (PIC): definido como a média aritmética dos preços de bens, serviços ou direitos, idênticos ou similares, apurados no mercado brasileiro ou de outros países, em operações de compra e venda, em condições de pagamento semelhantes. Tais preços, para serem válidos para comparação com os praticados pela empresa, devem ser negociados entre não vinculadas (BRASIL, 2002). O objetivo dessa metodologia é identificar os preços que são, normalmente, praticados no mercado. Para os casos de comparação com produtos não idênticos, a empresa necessita comprovar a similaridade entre os bens comparados;

(b) Método do Preço de Revenda menos Lucro (PRL): consiste em decompor o preço de venda do produto final, deduzido de outros custos não recuperáveis assumidos pelo importador, como fretes e impostos de importação e, do resultado, identificar a parcela referente ao preço do bem importado. O valor resultante, então, é deduzido do valor agregado no país e de margem de lucro definida pela legislação (BRASIL, 2002). A margem de lucro a ser deduzida do preço de revenda do produto final, para operações de importação de bens aplicados a processos produtivos, é de 60\% (BRASIL, 2002). A margem de $60 \%$ foi estabelecida para acobertar o chamado valor agregado ao bem importado durante o processo produtivo. Com a dedução da margem de lucro da parcela do preço praticado referente ao bem importado, chega-se ao preço parâmetro, que é tido como limite a ser considerado como custo de produção para fins de dedução das bases de cálculo dos tributos incidentes sobre a renda (BORGES, 2007). A maior vantagem desse método é o fato de que a empresa não necessita de documentos externos para a sua comprovação, bastando apresentar as notas fiscais de compra e as planilhas de cálculo utilizadas. Da mesma forma, para comprovar os preços de venda, basta disponibilizar relatórios de vendas e notas fiscais emitidas, juntamente com as planilhas de cálculo. A maior crítica a esse método é referente à presunção das margens de lucro, que, via de regra, varia de acordo com a empresa, com o seu mercado de 
atuação, suas estratégias de mercado e sua concorrência, entre outros fatores, não seguindo, provavelmente, o padrão estipulado pela lei (DE CARVALHO, 2007);

(c) Método do Custo de Produção mais Lucro (CPL): é definido como o custo médio de produção de bens, serviços ou direitos, idênticos ou similares, no país onde tiverem sido originariamente produzidos, acrescido dos impostos e taxas cobrados pelo referido país na exportação e de margem de lucro de $20 \%$, calculada sobre o custo apurado. A margem de lucro deve ser aplicada ao custo de produção antes da incidência de impostos e taxas cobrados sobre o valor dos bens no país de origem, sendo que o seu percentual não muda em função de tipo de produto ou de negócio da empresa fornecedora (BRASIL, 2002). O acréscimo de uma margem de lucro sobre o custo de produção é também conhecido como mark up. Para que esse método seja aceito, os custos de produção da empresa fornecedora vinculada ou de empresas não vinculadas que produzam bens similares devem ser demonstrados discriminadamente, por componente, inclusive, com a relação de fornecedores da empresa fornecedora, o que envolve uma série de documentos estrangeiros que devem ser traduzidos e legalizados no Brasil. As exigências em relação à legalização da documentação é um dos empecilhos para a aplicação desse método. Adicionalmente, questões estratégicas referentes à divulgação de custos produtivos também dificultam a sua aplicação. Assim como para o PRL, a principal crítica repousa no fato de haver uma margem de lucro pré-estabelecida generalizada (BARRETO, 2001).

Dentre os métodos propostos pela legislação brasileira, o PRL tem sido o mais utilizado pelas empresas. De acordo com a análise de Duarte (2005), o motivo para tal situação tem relação com o fato de que a aplicação do CPL tende a ser dificultada por questões de sigilo em relação à composição dos custos de produção, seja por parte de empresas vinculadas, seja por parte de empresas não vinculadas.

As principais diferenças verificadas entre a legislação brasileira e as metodologias sugeridas pela OCDE são resumidas na Figura 1.

REAd - Edição 68, Volume 17, No 1, jan/abr 2011 - p. 270-297 
TRANSFERÊNCIA EM OPERAÇÕES DE IMPORTAÇÃO

\begin{tabular}{|c|c|}
\hline OCDE & BRASIL \\
\hline Método de comparação dos preços não controlados & PIC (Método dos Preços Independentes Comparados) \\
\hline $\begin{array}{l}\text { Define que as questões negociais que porventura alterarem os } \\
\text { preços base de comparação devem ser considerados, para } \\
\text { não prejudicarem o cálculo. }\end{array}$ & $\begin{array}{l}\text { Considera ajustes referentes a prazos de pagamento e outros } \\
\text { que são comuns para os outros métodos. Não estabelece } \\
\text { qualquer ajuste aos preços base de comparação que sofrerem } \\
\text { ajustes decorrentes de acordos comerciais. }\end{array}$ \\
\hline Método do preço de revenda & PRL (Método do Preço de Revenda menos Lucro) \\
\hline $\begin{array}{l}\text { Não estabelece a margem de lucro a ser praticada, mas em } \\
\text { geral usa-se a margem normalmente verificada em operações } \\
\text { similares. }\end{array}$ & $\begin{array}{l}\text { Estabelece margens de lucro a serem deduzidas dos preços, } \\
\text { não considerando a situação específica de cada empresa. } \\
\text { ( } 20 \% \text { para revenda e } 60 \% \text { para produção). }\end{array}$ \\
\hline Método de custo mais lucro & CPL (Método do Custo de Produção mais Lucro) \\
\hline $\begin{array}{l}\text { Sugere que seja aplicada uma margem de lucro normalmente } \\
\text { verificada aos custos apurados. }\end{array}$ & $\begin{array}{l}\text { A partir da apuração dos custos de produção dos bens } \\
\text { importados, aplicar a margem de lucro de } 20 \% \text {. }\end{array}$ \\
\hline $\begin{array}{l}\text { Quarto Método } \\
\text { Quando nenhum dos três métodos anteriores for aplicável, } \\
\text { deve-se determinar uma maneira alternativa de efetuar esse } \\
\text { cálculo. }\end{array}$ & \\
\hline
\end{tabular}

Figura 1 - Comparação entre Métodos da OCDE e da Lei Brasileira

Fonte: elaborado pelos autores

\section{Método de Pesquisa}

Quanto à natureza, o presente trabalho classifica-se como pesquisa aplicada, visto que objetiva gerar conhecimentos para aplicação prática em relação a um problema específico. Quanto à abordagem do problema, o estudo pode ser classificado como qualitativo, por utilizar o ambiente natural para a coleta e análise de dados, descrevendo legislações e metodologias de cálculo, não necessitando utilizar técnicas estatísticas para chegar às conclusões. Os procedimentos de coleta de dados empregados incluíram entrevistas nãoestruturadas com colaboradores de diversos setores da organização relacionadas à problemática em estudo, observação direta e consulta aos registros documentais contábeis da empresa. Em particular, a coleta de dados se deu entre Março e Agosto de 2007. Neste período, foram entrevistados os responsáveis pela área tributária da empresa no período estudado (2002 a 2004): gerente de impostos, controller da fábrica e dois analistas de impostos responsáveis pela coleta de dados e apuração dos ajustes tributários referentes aos preços de transferência.

Do ponto de vista dos objetivos, este trabalho pode ser classificado como pesquisa exploratória, uma vez que busca propiciar maior familiaridade com o tema, através da análise de legislações e de dados fornecidos por uma empresa específica, além da aplicação de questionários e da condução de entrevistas com pessoas que trabalham em áreas relacionadas 
ao tema. Por tratar-se de uma análise crítica de uma situação já caracterizada, sendo que não há a participação ou influência do pesquisador nos fatos estudados, pelo ponto de vista dos procedimentos técnicos, o trabalho assume a forma de estudo de caso (YIN, 1994).

O tema é aplicável a empresas de qualquer ramo de atuação, desde que efetuem as operações internacionais com outras empresas do mesmo grupo econômico. Neste trabalho, o estudo de caso é efetuado em uma empresa multinacional do ramo agrícola. Para tanto, são efetuados o recálculo dos preços parâmetro e eventuais ajustes resultantes, com a aplicação da legislação vigente. Para essa fase do estudo, não são considerados os cálculos previamente efetuados pela empresa, em virtude de que o presente estudo não tem como objetivo analisar a sua correção. As planilhas da empresa são utilizadas apenas para a coleta dos dados necessários ao recálculo.

Em virtude de a empresa trabalhar com uma quantidade elevada de bens importados, as simulações são desenvolvidas com uma quantidade limitada de itens, sendo que os mesmos foram selecionados pelo critério de relevância dos valores totais de importação. Por motivos de confidencialidade, as informações fornecidas pela empresa foram alteradas e as descrições dos produtos considerados não são apresentadas.

A importação de bens na empresa estudada pode ter dois objetivos: a aplicação em processos produtivos e a revenda sem agregação de valor. Neste estudo, considera-se apenas as importação de componentes intercompanhia aplicados em processos produtivos, por representarem os maiores ajustes. Assim, não é simulada a metodologia aplicável às operações de importação de bens para revenda sem agregação de valor local.

Em todos os cálculos efetuados, considera-se a margem de divergência estabelecida pela legislação, para fins de obtenção do valor do ajuste devido. Quando houver divergência de, no máximo, $5 \%$ entre o preço parâmetro calculado e aquele verificado nas importações, não há exigência de ajustes dos custos ou das bases de cálculo de tributos (BRASIL, 2002).

\section{Resultados}

A empresa selecionada para a execução do estudo de caso é uma multinacional e possui negócios ao redor do mundo, com cerca de 47 mil funcionários e mais de 30 fábricas localizadas em mais de doze países. As informações disponibilizadas pela empresa são referentes aos anos de 2002 a 2004, sendo que seus dados foram alterados por questões de 
sigilo. A seleção das informações utilizadas no estudo levou em consideração os insumos que sofriam os maiores ajustes dentro da base de dados.

A empresa possui três unidades fabris estabelecidas no Brasil. Por atuar no mundo inteiro, a empresa faz negócios entre as suas unidades, efetuando exportações e importações de equipamentos, peças e motores que são aplicados nos seus produtos. A unidade brasileira importa partes, peças, componentes e acessórios, que são aplicados à fabricação de máquinas e equipamentos agrícolas e também revendidos no mercado nacional, para fins de manutenção e assistência técnica aos produtos já comercializados no país (tanto os produzidos localmente quanto os importados e revendidos).

Dentre as três metodologias de cálculo propostas pela legislação atualmente vigente, a empresa não disponibilizou informações suficientes para a simulação do PIC. As duas metodologias restantes, o PRL 60 e o CPL, foram simuladas com base nos preços e custos médios ponderados fornecidos. A comparação dos ajustes resultantes da aplicação das duas metodologias, de acordo com a normatização atualmente vigente (IN SRF 243/02), demonstra que o CPL é a opção menos desvantajosa.

A afirmação de que o CPL é a opção menos desvantajosa (e não a mais vantajosa) deve-se ao fato de que, por mais baixos que sejam os preços parâmetros apurados por qualquer uma das metodologias, em nenhuma hipótese o resultado da empresa será ajustado para menor (o que reduziria a tributação resultante e seria, portanto, vantajosa). Em outras palavras, ou a empresa não sofre qualquer alteração do seu resultado ou sofre ajustes que aumentam os resultados do período, com resultante aumento da tributação.

Adicionalmente, foi simulada a aplicação do PRL 60 de acordo com a IN SRF 32/01, que foi revogada pela IN 243/02, com o objetivo de verificar a relevante diferença entre as fórmulas de cálculo propostas, para a mesma metodologia, pelas duas normatizações. Esse cálculo se mostra interessante visto que conforme Becker e Novaski (2008), a aplicação dessa metodologia (IN243/02) é passível de discussão, mesmo para o período da sua vigência, haja vista que a metodologia de cálculo desta IN difere daquela referida na lei 9.430/96 e suas alterações. A definição dessa questão deve ser definida pelo Conselho de Contribuintes ou pelo Judiciário, que deverão avaliar a ilegalidade da IN.

Pupo (2007) afirma que atos normativos não podem alterar normas expressas em lei, logo, a simulação pretende demonstrar que a IN anteriormente vigente, e que estava de acordo com a REAd - Edição 68, Volume 17, No 1, jan/abr 2011 - p. 270-297 
lei, resultava em ajuste relevantemente diferente daquele resultante da normatização atualmente vigente. No estudo de caso efetuado, o resultado da sua aplicação não somente é inferior, como nulo.

A Tabela 1 demonstra o resumo do cálculo dos preços parâmetro de acordo com as três metodologias simuladas, que seguem as regras sugeridas pela legislação brasileira. Os ajustes desta tabela são os que devem ser aplicados às bases de cálculo dos tributos.

Tabela 1 - Simulação dos Métodos de Cálculo de Preços de Transferência

\begin{tabular}{|c|c|}
\hline CPL (de acordo com IN SRF 243/02) & $\begin{array}{c}\text { Insumo } \\
\text { Exemplo } \\
\end{array}$ \\
\hline Custo Médio de Produção do Insumo Importado (no fornecedor) (a) & 19.172 \\
\hline Impostos e Tributos sobre Venda do Insumo no País de Origem (b) & 2.421 \\
\hline Fretes e Tributos Assumidos pelo Importador que não Compõem o Custo de Produçao do Insumo Importado (c) & 2.690 \\
\hline Margem de Lucro definida pela legialação $(20 \%)(\mathrm{d}=\mathrm{a} * 20 \%)$ & 3.834 \\
\hline Preço Médio Ponderado Praticado do Insumo Importado (e) & 26.896 \\
\hline Preço Parâmetro (antes da margem de divergência) $(\mathrm{f}=\mathrm{a}+\mathrm{b}+\mathrm{d})$ & 25.427 \\
\hline Preço Parâmetro (após margem de divergência) (g) & 25.427 \\
\hline Ajuste Devido por Unidade de Insumo Importado Adquirida (Adição ao Custo) (h=e-g, se $\mathrm{h}<0$ considerar 0)) & 1.470 \\
\hline Quantidade de Insumo Importado Adquirida (i) & 106 \\
\hline Ajuste Total Devido sobre Aquisição de Insumo Importado (Adição ao Custo) ( $\mathrm{j}=\mathrm{i} * \mathrm{~h})$ & 155.191 \\
\hline PRL 60 (de acordo com IN SRF 243/02) & $\begin{array}{c}\text { Insumo } \\
\text { Exemplo } \\
\end{array}$ \\
\hline Preço Médio pond. Praticado na Importação do Insumo (a) & 26.896 \\
\hline Preço Médio pond. Líquido de Revenda do prod. Final para Não Vinculadas (b) & 97.935 \\
\hline Custo Médio pond. de Produção do prod. Final (c) & 85.024 \\
\hline$\%$ Custo insumo no Custo de Produção do prod. Final $(\mathrm{d}=\mathrm{a} / \mathrm{b})$ & $32 \%$ \\
\hline Valor Agregado ao insumo (média ponderada) $(\mathrm{e}=\mathrm{c} *(1-\mathrm{d}))$ & 58.128 \\
\hline Valor do insumo no Preço de Revenda do prod. Final $(\mathrm{f}=\mathrm{b} * \mathrm{~d})$ & 30.980 \\
\hline ( - ) mrg. de Lucro de $60 \%$ (sobre valor do insumo no preço do prod. final) $(\mathrm{g}=\mathrm{f} * 60 \%)$ & 18.588 \\
\hline Preço Parâmetro (h=f-g) & 12.392 \\
\hline Ajuste Devido por un. antes da mrg. de Divergência (Adição ao Custo) (i=b-h) & 14.504 \\
\hline Ajuste Devido por un. de insumo Adquirida após mrg. de Divergência (Adição ao Custo) (j=se i/a <1,05, j=0) & 14.504 \\
\hline Quantidade de insumo Adquirida $(\mathrm{k})$ & 106 \\
\hline Ajuste Total Devido sobre Aquisição de insumo (Adição ao Custo) (l=i*k) & 1.531 .635 \\
\hline PRL 60 (de acordo com IN SRF 32/01) & $\begin{array}{c}\text { Insumo } \\
\text { Exemplo } \\
\end{array}$ \\
\hline Preço Médio pond. Praticado na Importação do Insumo (a) & 26.896 \\
\hline Preço Médio Pond. de Revenda do prod. Final para Não Vinculadas Menos Descontos incondicionais (b) & 111.254 \\
\hline Preço Médio Pond. de Revenda do prod. Final para Não Vinculadas Menos Descontos incondicionais, Frete e Tributos (c) & 97.935 \\
\hline Custo Médio pond. de Produção do prod. Final (d) & 85.024 \\
\hline Valor Agregado ao insumo (média ponderada) $(\mathrm{e}=\mathrm{d}-\mathrm{a})$ & 58.128 \\
\hline Mrg. de Lucro de 60\% (sobre Preço Médio de Revenda Líquido de Desc. Incond. Menos o Valor Agregado (f=(b-e)*60\%) & 31.876 \\
\hline Preço Parâmetro $(\mathrm{g}=\mathrm{c}-\mathrm{f})$ & 66.059 \\
\hline Ajuste Devido por un. antes da mrg. de Divergência (Adição ao Custo) $(\mathrm{h}=\mathrm{g}$-a) & - \\
\hline Ajuste Devido por un. de insumo Adquirida após mrg. de Divergência (Adição ao Custo) (i=se h/a <1,05, i=0) & - \\
\hline Quantidade de insumo Adquirida (j) & 106 \\
\hline Ajuste Total Devido sobre Aquisição de insumo (Adição ao Custo) $(\mathrm{k}=\mathrm{j} * \mathrm{i})$ & - \\
\hline
\end{tabular}

Fonte: elaborado pelos autores

REAd - Edição 68, Volume 17, No 1, jan/abr 2011 - p. 270-297 
Considerando os tributos que incidem sobre a renda no Brasil, IRPJ e a CSLL, cujas alíquotas são 25\% (alíquota máxima possível) e 9\%, respectivamente (BRASIL, 1999), os tributos incrementais, resultantes dos ajustes resultantes das metodologias propostas, são sumarizados pela Tabela 2.

A referida tabela mostra que o PRL 60, de acordo com a IN SRF 243/02, é o método que resulta no maior valor de ajuste. Enquanto o ajuste resultante da aplicação do CPL é de \$52.765, o ajuste resultante da aplicação do PRL é de \$520.756. Já o PRL 60, simulado de acordo com a IN SRF 32/01, não resulta em ajuste.

Tabela 2 - Tributos Incrementais Resultantes das Metodologias de Cálculo de Preços de Transferência

\begin{tabular}{|l|c|c|r|r|r|}
\cline { 2 - 6 } \multicolumn{1}{c|}{} & \multicolumn{2}{c|}{ IRPJ (Alíquota de 25\%) } & \multicolumn{2}{c|}{ CSLL (Alíquota de 9\%) } & \multicolumn{1}{c|}{ TOTAL } \\
\hline Métodologia Aplicada & $\begin{array}{c}\text { Aumento Base de } \\
\text { Cálculo }\end{array}$ & $\begin{array}{c}\text { Incremento } \\
\text { Tributário }\end{array}$ & $\begin{array}{c}\text { Aumento Base de } \\
\text { Cálculo }\end{array}$ & $\begin{array}{c}\text { Incremento } \\
\text { Tributário }\end{array}$ & $\begin{array}{c}\text { Incremento } \\
\text { Tributário }\end{array}$ \\
\hline Método PRL 60 (IN SRF 243/02) & 1.531 .635 & 382.909 & 1.531 .635 & 137.847 & $\mathbf{5 2 0 . 7 5 6}$ \\
\hline Método CPL (IN SRF 243/02) & 155.191 & 38.798 & 155.191 & 13.967 & $\mathbf{5 2 . 7 6 5}$ \\
\hline Método PRL 60 (IN SRF 32/01) & - & - & - & - & - \\
\hline
\end{tabular}

Em relação ao CPL, cabe ressaltar que os resultados podem variar de acordo com cada empresa, em virtude das margens de lucro reais aplicadas pelos seus fornecedores. Nessa simulação, as margens aplicadas pelas unidades vinculadas fornecedoras de insumos para a definição do preço de venda não chegam a $20 \%$, logo, são menores do que a margem fixa estipulada para o método. Dessa forma, a margem fixada não é prejudicial à empresa estudada, nesse método. Ao contrário, contribui positivamente, pois reduz o valor de ajuste.

O PRL 60, normatizado pela IN SRF 32/01, que não é válida atualmente, resultou em ajuste nulo. A importância da sua simulação se deve à comparação do PRL 60 nas duas versões do instrumento legal que normatiza a Lei 9.430/96. Pela lógica, qualquer normatização da citada lei deveria apenas detalhar o que já fora definido na própria lei, não alterando de maneira relevante os resultados esperados quando da interpretação da lei. Entretanto, não é isso que se verifica ao efetuarmos a simulação. É devido a tamanha discrepância entre as duas metodologias de cálculo que está em andamento o questionamento da legalidade da IN243/02.

A comparação entre os dois métodos disponibilizados pela legislação atualmente vigente demonstra que, para o estudo de caso efetuado, o CPL é a opção menos desvantajosa, visto 
que resulta no menor ajuste ao resultado. Este resultado seria diferente caso as margens aplicadas pelo fornecedor vinculado estabelecido em outra jurisdição fiscal fossem maiores do que os $20 \%$ estabelecidos na lei.

\section{Discussão}

O objetivo principal da legislação que trata sobre Preços de Transferência entre empresas vinculadas é identificar se os preços praticados estão de acordo com os preços praticados em operações normais de mercado, em que não há vínculo entre as partes envolvidas. Considerando a discrepância observada entre os ajustes resultantes das duas metodologias atualmente vigentes para o tipo de operação em estudo, o PRL 60 e o CPL normatizados pela IN SRF 2443/02, pode-se perceber que há relevante diferença entre os preços parâmetros definidos por cada um. Como ambos possuem como princípio básico o do preço justo e têm como objetivo encontrar o valor de mercado dos itens importados, não deveriam resultar em preços parâmetro tão distintos.

É aceitável o fato de que é necessário adotar uma metodologia de cálculo destes preços parâmetro, visto que não haveria uma forma mais prática de efetuar as verificações e os controles tributários dessas operações. Entretanto, a partir da relevância da diferença entre os preços obtidos a partir dos dois métodos, aplicados a uma mesma base de dados, presume-se que as metodologias não alcançam o seu objetivo plenamente. Caso se suponha que uma das metodologias tenha chegado ao valor de mercado, fica evidente que a outra resultou em um valor significativamente distinto do devido.

As metodologias de cálculo de preço apresentadas mostram que há diversos fatores subjetivos a serem considerados a fim de identificar o melhor preço a ser praticado, e que esse preço pode mudar de acordo com o mercado em que os bens, serviços ou diretos são vendidos. $\mathrm{O}$ fato de as metodologias resultarem preços parâmetros tão distintos leva a presumir que não chegam ao valor justo de mercado, pois, caso assim o fizessem, não poderiam resultar em valores tão diferentes.

O fato de o CPL considerar uma margem de lucro de $20 \%$ para o cálculo de preços parâmetro deve ser considerado, visto que o ajuste resultante da sua aplicação depende diretamente da comparação entre esse percentual e a margem de lucro efetivamente aplicada pelo fornecedor de insumos. Caso a margem de lucro efetiva seja maior do que a estabelecida pela lei vigente, o ajuste resultante tenderá a ser significativamente maior. Assim, o método CPL não será, REAd - Edição 68, Volume 17, No 1, jan/abr 2011 - p. 270-297 
necessariamente, o mais vantajoso em todas as situações, visto que o ajuste aumenta na medida em que a margem de lucro da unidade fornecedora aumenta. Isso se deve ao fato de quanto maior é a margem de lucro a ser deduzida do custo de produção, menor será o custo ao qual se deve adicionar a margem fixa de lucro definida pela Lei 9.430/96, de 20\%. ou seja, menor será o preço parâmetro comparável ao preço praticado na importação de bens para aplicação em processos produtivos. Comprova-se, portanto, que embora o CPL seja a melhor alternativa para a situação específica estudada nesse trabalho, o resultado pode ser diferente de acordo com a situação específica de cada fornecedor.

O método PRL 60, especificado na IN SRF 243/02, por sua vez, resulta em um ajuste significativamente diferente daquele obtido pelo método CPL. Tamanha diferença justifica-se pela margem de lucro de $60 \%$, visto que é uma margem de lucro alta e raramente praticável pelas empresas, e pelo fato de essa margem ser aplicada sobre a parte do preço líquido de venda proporcional ao custo do bem importado no custo total do produto final vendido (BORGES, 2007).

A comparação desse ajuste com o resultante do cálculo do PRL 60 definido na IN SRF 32/01, que era válida até o surgimento da IN SRF 243/02, mostra que há relevante diferença entre as metodologias. Essa comprovação ocorre ao comparar os ajustes referentes aos mesmos dados que formam a base de cálculo quando a eles é aplicada cada uma das metodologias e decorre, principalmente, do fato de que a IN SRF 32/01 não estabelece a consideração do percentual de participação do insumo no custo do produto final em que o item importado é aplicado (BRASIL, 2001, 2002).

Há grande polêmica em torno dos ajustes resultantes das fórmulas de cálculo propostas em cada uma das Instruções Normativas. Nesse trabalho, não são feitos comentários profundos em relação a tais discussões, em virtude de que prolongariam demais as explicações, mas a Figura 2 sumariza as principais diferenças entre os cálculos propostos.

REAd - Edição 68, Volume 17, No 1, jan/abr 2011 - p. 270-297 


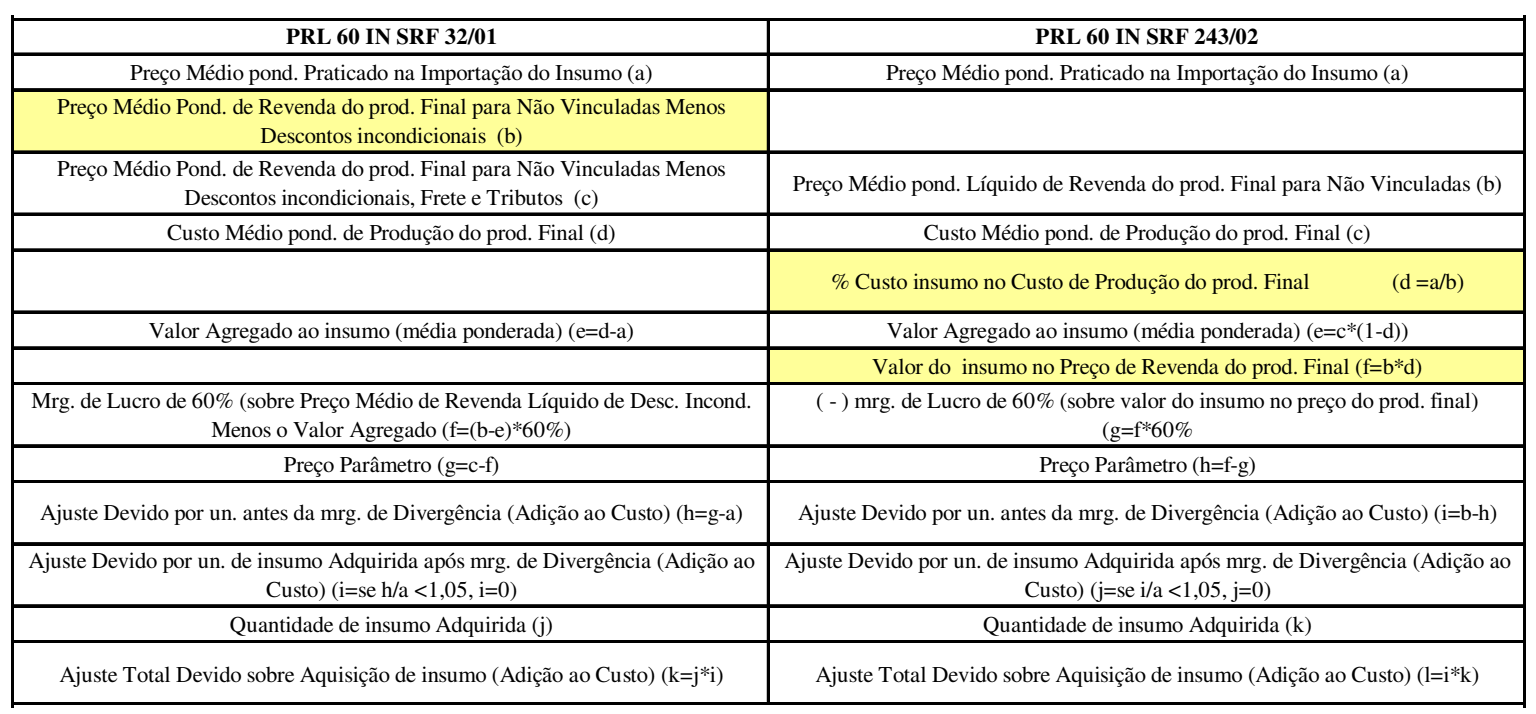

Figura 2 - Comparação entre PRL 60 normatizado pelas INs SRF 32/01 e 243/02

Fonte: elaborado pelos autores

A IN SRF 243/02 define que a margem deve ser aplicada ao preço de revenda líquido de descontos incondicionais concedidos, fretes e tributos incidentes sobre a importação, devendo ser considerada somente a parte do preço referente à participação do bem importado (e não sobre o valor integral do preço líquido de venda, como na IN SRF 32/01) (BRASIL, 2001, 2002). O maior questionamento verificado em relação à nova regra refere-se ao fato de que a Lei 9.430/96 determina a aplicação do percentual de 60\% de margem de lucro sobre a totalidade do preço de venda (BRASIL, 1996), enquanto que a IN 243/02 determina a aplicação desse percentual apenas sobre a parte proporcional ao custo do bem importado no custo total do produto final revendido.

Por conta da divergência verificada entre a Lei 9.430/96 e a IN SRF 243/02, sustenta-se que a instrução normativa vigente é ilegal. Segundo as argumentações dos seus questionadores, a IN majorou um tributo sem ter permissão legal para tanto, por ter reduzido a dedutibilidade dos custos dos bens e por divergir da lei que deveria regulamentar (BORGES, 2007).Considerando a hierarquia da legislação, verifica-se que a Lei 9.430/96 deve prevalecer sobre as instruções normativas, que têm como principal função a especificação das metodologias já definidas em lei. Não é correto, portanto, que uma IN altere os conceitos ou princípios já definidos em lei (BECKER; NOVASKI, 2008; BORGES, 2007; GALHARDO; MONGUILOD, 2007). 
Adicionalmente, pode-se mencionar a questão referente à fixação de uma margem de lucro a ser considerada. Em virtude de as margens efetivas variarem de empresa para empresa, em função de fatores como mercado, estratégia, etc., a própria lei que introduziu as regras sobre Preços de Transferência estaria indo de encontro ao princípio do preço justo. A fixação da margem faz com que não seja considerado o preço praticado efetivamente pelo mercado, mas aquele definido a partir de uma margem mínima de lucro definida pela legislação e que não varia de acordo com as características próprias de cada contribuinte (DE VASCONCELLOS, 2007).

Em relação ao método PIC, que não foi simulado nesse trabalho, ressalta-se que, para o caso de insumos importados com similares no mercado, a comparação pode ser mais vantajosa que as demais metodologias.

A comparação entre os métodos CPL e PRL 60 determinados pela Lei 9.430/96 e normatizados pela IN SRF 243/02 mostra a divergência entre os dois cálculos, considerando o estudo de caso apresentado. Percentualmente, o preço parâmetro obtido pelo PRL 60 representa apenas $49 \%$ do preço obtido pelo CPL, conforme demonstrado na Tabela 3. Considerando que quanto menor é o preço parâmetro maior é o ajuste resultante, e que há uma tendência de que o CPL resulte em ajuste menor do que o PRL, conclui-se que o contribuinte deve optar pelo CPL sempre que tenha condições de comprová-lo.

Tabela 3 - Comparação dos Métodos de Cálculo de Preços de Transferência

\begin{tabular}{|l|c|c|r|r|r|}
\cline { 2 - 6 } \multicolumn{1}{c|}{} & \multicolumn{2}{c|}{ IRPJ (Alíquota de 25\%) } & \multicolumn{2}{c|}{ CSLL (Alíquota de 9\%) } & \multicolumn{1}{c|}{ TOTAL } \\
\hline Métodologia Aplicada & $\begin{array}{c}\text { Aumento Base de } \\
\text { Cálculo }\end{array}$ & $\begin{array}{c}\text { Incremento } \\
\text { Tributário }\end{array}$ & $\begin{array}{c}\text { Aumento Base de } \\
\text { Cálculo }\end{array}$ & $\begin{array}{c}\text { Incremento } \\
\text { Tributário }\end{array}$ & $\begin{array}{c}\text { Incremento } \\
\text { Tributário }\end{array}$ \\
\hline Método PRL 60 (IN SRF 243/02) & 1.531 .635 & 382.909 & 1.531 .635 & 137.847 & $\mathbf{5 2 0 . 7 5 6}$ \\
\hline Método CPL (IN SRF 243/02) & 155.191 & 38.798 & 155.191 & 13.967 & $\mathbf{5 2 . 7 6 5}$ \\
\hline Método PRL 60 (IN SRF 32/01) & - & - & - & & - \\
\hline
\end{tabular}

Fonte: elaborado pelos autores

\section{Conclusão}

A primeira lei brasileira sobre o tema surgiu há mais de dez anos e, a partir de então, passou por reformulações diversas vezes. Embora a Lei 9.430/96 tenha sofrido alterações através de outras normas legais de igual hierarquia tributária desde a sua inserção na legislação, tais reformulações não foram suficientes para eliminar as discussões existentes sobre o tema. 
Comparações entre a normatização internacionalmente aceita e a legislação vigente no Brasil permitem concluir que a norma brasileira é abrangente e restritiva, impondo margens de lucro fixas que não levam em conta as características de cada empresa sujeita as suas regras.

A lei vigente determina as metodologias passíveis de aplicação para os cálculos de preços parâmetro, mas não especifica como cada uma delas deve ser aplicada. Para tanto, há legislações de menor hierarquia, chamadas de instruções normativas da SRF. De acordo com tais instrumentos legais, o contribuinte tem a opção de efetuar os cálculos utilizando três metodologias de cálculo disponíveis e optar pelo que resultar em menor ajuste da base de base de cálculo. Para reduzir os impactos tributários resultantes de ajustes relacionados aos preços de transferência, as empresas devem utilizar essa possibilidade e efetuar os cálculos através das três metodologias disponibilizadas, quando isso for possível. Conforme discussão dos resultados do estudo de caso efetuado, o método CPL normalmente será menos desvantajoso do que o PRL 60. Em relação ao PIC, a tendência é a mesma, visto que esse método busca produtos similares e verifica o valor praticado no mercado, não necessitando de uma metodologia de cálculo que tente se aproximar dos valores corretos.

Para as situações em que a empresa não aplica todos os métodos disponibilizados por motivo de dificuldade de aplicação dos mesmos, geração de documentação comprobatória ou por questões estratégicas de sigilo de informações, resta como alternativa a sua utilização para um grupo restrito de bens. A escolha dos bens a que estes métodos mais complexos seriam aplicados poderia ocorrer através de critério de relevância dos valores envolvidos, por exemplo.

O objetivo do trabalho, que é a identificação dos impactos resultantes de limitações impostas pela legislação brasileira que trata sobre preços de transferência em operações de importação de bens aplicados à produção, foi completamente atingido. A simulação dos métodos de cálculo apresentada permitiu que fossem identificados ajustes devidos e impactos tributários resultantes.

A principal conclusão é a de que a temática dos preços de transferência depende de muitas variáveis individuais, as quais devem ser estudadas e analisadas caso a caso, de acordo com as particularidades envolvidas em cada situação. Técnicas de formação de preços não são aplicadas pela legislação brasileira, que estabelece regras fixas, de acordo com dadas 
situações, e as sugeridas comparações de preços não ocorrem, o que colabora para que a regra do princípio justo não seja plenamente cumprida.

Devido à complexidade do assunto e todos os detalhes de cálculo envolvidos, há diversos pontos da legislação que não foram estudados com profundidade neste trabalho. Em virtude dos resultados obtidos, sugere-se que no futuro sejam efetuadas simulações mais amplas do que a apresentada nesse trabalho. Nessa oportunidade, analisam-se somente as operações de importação de bens aplicados a processos produtivos. Sugere-se a simulação dos mesmos cálculos para operações de importação para revenda, além da consideração de operações de exportação.

Os impactos resultantes de possíveis diferenças de cálculo de custos produtivos entre as unidades, especialmente aquelas resultantes de diferenças entre as legislações de países envolvidos, não foram considerados nas simulações. Sugere-se que sejam avaliados os ajustes que deveriam ser feitos para a sua adaptação à legislação brasileira. Adicionalmente, seria interessante analisar as possíveis diferenças não ajustáveis entre os métodos de custos considerados entre duas unidades vinculadas que efetuam operações de transferência.

Em relação à ilegalidade das Instruções Normativas, Pupo (2007) comenta que a jurisprudência dos tribunais brasileiros é uníssona no sentido de que atos normativos não podem dispor diferentemente ou extrapolar uma lei, devido ao princípio da estrita legalidade. Sugere-se que a questão da ilegalidade da IN atualmente vigente seja analisada com profundidade, a fim de avaliar o risco assumido por uma empresa que discorde da regra atual e opte por efetuar cálculos alternativos. Já existem diversos estudos efetuados neste sentido, especialmente por profissionais da área de direito tributário, mas poder-se-ia adicionar a questão do objetivo principal da legislação, que é a definição do preço justo, ou preço de mercado, para cada insumo importado. Questões subjetivas no cálculo de preços e as principais técnicas de cálculo de preços utilizadas pelas empresas poderiam ser consideradas em um estudo específico, o que poderia resultar na comprovação de que a legislação propõe ou não metodologias que resultem em preço parâmetro próximo ao valor de mercado.

Nesta oportunidade, não foram avaliados com profundidade os acordos bitributação. Seria interessante a avaliação de como esses acordos poderiam influenciar nos ajustes de preços de transferência e quais são as regras passíveis de serem aplicadas no Brasil.

REAd - Edição 68, Volume 17, No 1, jan/abr 2011 - p. 270-297 
Por fim, sugere-se que seja efetuado um estudo mais aprofundado sobre a adoção de margens de lucro com percentuais fixos na legislação brasileira. Tal estudo, aplicado a um setor empresarial ou empresa específica, poderia auxiliar no entendimento e comprovação de que a legislação pode ser prejudicial ou benéfica ao contribuinte, dependendo das margens efetivamente praticadas.

\section{REFERÊNCIAS}

AL-ERYANI, M.; ALAM, P.; AKHTER, S.H. Transfer Pricing Determinants of U.S. Multinationals. Journal of International Business Studies, v. 21, n. 3, p. 409-425, 1990.

ALEXANDRINO, M.; PAULO, V. Direito Tributário na Constituição e no STF. Niterói, RJ: Editora Impetus, 2005. 237 p.

BALDENIUS, T.; MELUMAD, N. D.; REICHELSTEIN, S. Integrating Managerial and Tax Objectives in Transfer Pricing. The Accounting Review. v. 79, n. 3, p. 591-615, Jul 2004.

BARRETO, P. A. Imposto sobre a Renda e Preços de Transferência. São Paulo, SP: Dialética, 2001.

BECKER, R.L., NOVASKI, A.A.M. Receita Federal confirma inaplicabilidade da IN 243/02 para o ano-calendário de 2002. Anexo Biblioteca Informa, $n^{\circ} 1.994,27$ de janeiro - 9 de fevereiro de 2008. Pinheiro Neto Advogados. Disponível em: $<$ http://www.pinheironeto.com.br/upload/tb_pinheironeto_artigo/pdf/130208153542anexo_bi 1994.pdf>. Acesso em: 25 mar. 2010.

BERNARD, A.B.; JENSEN, J.B.; SCHOTT, P.K. Transfer Pricing by U.S.-based Multinational Firms. Tuck School of Business Working Paper No. 2006-33, 2006.

BOMFIM, E. de A.; PASSARELli, J. Custos e Formação de Preços. São Paulo, SP: Editora Thomson IOB, Ed. 4, 2006.

BORGES, A. S. O Método do Preço de Revenda Menos Lucro - PRL na Legislação Brasileira. In: BORGES, A. S.; FERNANDES, E. C.; PEIXOTO, M. M. (Coord.). Manual dos Preços de Transferência no Brasil: celebração dos 10 anos de vigência da lei. São Paulo. MP Editora, 2007. 350 p., p. 59-75.

BORKOWSKI, S.C. The transfer pricing concerns of developed and developing countries. The International Journal of Accounting, v. 32, n. 3, p. 321-336, 1997. 
BRASIL. Lei $n^{0}$ 9.430, de 27 de dezembro de 1996. Dispõe sobre a legislação tributária federal, as contribuições para a seguridade social, o processo administrativo de consulta e dá outras providências. Disponível em: <http://www.receita.fazenda.gov.br >. Acesso em: 15 set. 2007.

. Decreto 3.000, de 26 de março de 1999, denominado de Regulamento do Imposto sobre a Renda e Proventos de Qualquer Natureza. Disponível em: <http://www.receita.fazenda.gov.br>. Acesso em: 15 set. 2007.

Instrução Normativa SRF no 32, de 30 de Março de 2001. Dispõe sobre os preços a serem praticados nas operações de compra e venda de bens e direitos, efetuadas por pessoa física ou jurídica residente ou domiciliada no Brasil, com pessoa física ou jurídica residente ou domiciliada no exterior, consideradas vinculadas. Disponível em: <http://www.receita.fazenda.gov.br>. Acesso em 15 set. 2007.

Instrução Normativa SRF $n^{0}$ 243, de 11 de Novembro de 2002. Dispõe sobre os preços a serem praticados nas operações de compra e de venda de bens, serviços ou direitos efetuadas por pessoa física ou jurídica residente ou domiciliada no Brasil, com pessoa física ou jurídica residente ou domiciliada no exterior, consideradas vinculadas. Disponível em: <http://www.receita.fazenda.gov.br>. Acesso em: 15 set. 2007.

BREM, M.; TUCHA, T.A. On Transfer Pricing Conceptual Thoughts on the Nature of the Multinational Firm. IIMA Working Paper No. 2005-11-03, 2005.

BUCKLEY, P.J.; HUGHES, J.F. Incentives to transfer profits: a Japanese perspective. Applied Economics, v. 33, n. 15, p. 2009-2015, 2001.

CARTER, W. K.; MALONEY, D. M.; VRANKEN, M. H. Van. The problems of transfer pricing. Journal of Accountancy, v. 186, n. 1, p. 37, Jul 1998.

CHAN, K.H.; CHOW, L. An empirical study of tax audits in China on international transfer pricing. Journal of Accounting and Economics, v. 23, n. 1, p. 83-112, 1997.

DE CARVALHO, C. V. Anotações sobre o Método do Custo de Produção Mais Lucro (CPL). In: BORGES, A. S.; FERNANDES, E. C.; PEIXOTO, M. M. (Coord.). Manual dos Preços de Transferência no Brasil: celebração dos 10 anos de vigência da lei. São Paulo: MP Editora, 2007. 350 p., pg. 77-83.

DE VASCONCELlOS, R. F. Preços de Transferência e Acordos de Bitributação. In: BORGES, A. S.; FERNANDES, E. C.; PEIXOTO, M. M. (Coord.). Manual dos Preços de

REAd - Edição 68, Volume 17, No 1, jan/abr 2011 - p. 270-297 
Transferência no Brasil: celebração dos 10 anos de vigência da lei. São Paulo: MP Editora, 2007. 350 p., p. 161-189.

DUARTE, S. I. Preços de Transferência: Aspectos Polêmicos da Legislação Brasileira. São Paulo: Saint Paul Institute of Finance. 2005.

ERNST \& YOUNG. 2009 Global transfer pricing survey. Disponível em: $<$ http://www.eoy-

award.com/Publication/vwLUAssets/2009_Global_transfer_pricing_survey/\$FILE/Ernst\%20 \&\%20Young\%202009\%20Global\%20transfer\%20pricing\%20survey.pdf>. Acesso em: 25 mar. 2010.

FEINSCHREIBER, R.; KENT, M. A Guide to Global Transfer Pricing Strategy. Journal of Corporate Accounting \& Finance, v. 12, n. 6, p. 29-34, 2001.

FERNANDES, E. C. Conceitos Básicos Referentes ao Controle Fiscal dos Preços de Transferência. In: BORGES, A. S.; FERNANDES, E. C.; PEIXOTO, M. M. (Coord.). Manual dos Preços de Transferência no Brasil: celebração dos 10 anos de vigência da lei. São Paulo: MP Editora, 2007. 350 p., p. 13-34.

GALHARDO, L. R.; MONGUILOD, A. C. A Ilegalidade do Mecanismo de Aplicação do Método PRL sob a IN 243/02. In: BORGES, A. S.; FERNANDES, E. C.; PEIXOTO, M. M. (Coord.). Manual dos Preços de Transferência no Brasil: celebração dos 10 anos de vigência da lei. São Paulo: MP Editora, 2007. 350 p., p. 231-256.

JOHRI, L.M.; PETISON, P. Value-based localization strategies of automobile subsidiaries in Thailand. International Journal of Emergin Markets, v. 3, n. 2, p. 140-162, 2008.

MANGUERON, M. V. L. Processo de Tomada de Decisão Sob Incerteza em Investimentos Internacionais na Exploração \& Produção de Petróleo: Uma Abordagem Multicritério. Rio de Janeiro: UFRJ, 2003. Dissertação (Mestrado em Ciências em Planejamento Energético), Faculdade de Ciências, Universidade Federal do Rio de Janeiro, 2003.

MATTEI, F.; WULFKUHLER, K. Managing transfer-pricing risk. ICIS Chemical Business Americas, ABI/INFORM Global; v. 270, n. 18, p. 22, Nov 13-Nov 19, 2006.

MEHAFDI, M. The ethics of international transfer pricing. Journal of Business Ethics. v. 28, n. 4. p. 365-381, 2000.

REAd - Edição 68, Volume 17, No 1, jan/abr 2011 - p. 270-297 
NEIGHBOUR, J. Transfer Pricing: Keeping it at arms' length. Organisation for Economic Cooperation and Development. The OECD Observer; v. 230; p. 29-30, 2002.

OUENNICHE, J.; VILLEGAS, F. A general unconstrained model for transfer pricing in multinational supply chains. European Journal of Operational Research. v. 187; p. 829$856,2008$.

OECD. About the OECD. 2008. Disponível em: <http://www.oecd.org/dataoecd/15/33/34011915.pdf >. Acesso em: 25 mar. 2010.

Transfer Pricing Guidelines for Multinational Enterprises and Tax Administrations. Paris: OECD, 2009.

OYELERE, P.B.; TURNER, J.D. A survey of transfer pricing practices in UK banks and building societies. European Business Review, v. 12, n. 2, p. 93-99, 2000.

PORTER, M. E. What is Strategy? Harvard Business Review. Boston, v. 74, n. 6, p. 61-68, nov./dec. 1996.

PUPO, M. B. Preços de Transferência e os Limites Constitucionais dos Ajustes do Lucro. In: BORGES, A. S.; FERNANDES, E. C.; PEIXOTO, M. M. (Coord.). Manual dos Preços de Transferência no Brasil: celebração dos 10 anos de vigência da lei. São Paulo: MP Editora, 2007. 350 p., p. 205-229.

SADIQ, K. The Traditional Rationale of the Arm's Length Approach to Transfer Pricing Should the Separate Accounting Model be Mantained for Modern Multinational Entities? Journal of Australian Taxation, v. 7, n. 2, p. 196-250, 2004.

SANTOS, J. J. Fundamentos de Custos para Formação do Preço e do Lucro. 5.ed. São Paulo: Atlas S.A., 2005.

SCHOUERI, L. E. Preços de Transferência no Direito Tributário Brasileiro. São Paulo: Ed. Dialética, 1999.

WRAPPE, S. C.; MILANI, K.; JOY, J. The transfer price is right ... or is it? Strategic Finance, v. 81, n. 1; p. 38-43, 1999.

YIN, R.K. Case Study Research: Design and Methods. 2.ed. Thousand Oaks: Sage Publications, 1994.

REAd - Edição 68, Volume 17, No 1, jan/abr 2011 - p. 270-297 
ZDANOWICZ, J.; PAK, S.; SULLIVAN, M. Brazil-United States Trade: Capital Flight Through Abnormal Pricing. The International Trade Journal, v. 13, n. 4, p. 423-443, 1999.

\begin{abstract}
RESUMO
$\mathrm{Na}$ medida em que a economia global se expande e os mercados se tornam mais abertos para os investimentos, as empresas dividem atividades entre as suas unidades estabelecidas em diferentes países. A determinação dos preços praticados em operações de transferência entre companhias associadas situadas em diferentes jurisdições fiscais é chamada de Preços de Transferência. Para fins tributários, os preços de transferência determinam o valor de receita que cada empresa recebe e o referente valor de tributos incidentes sobre receitas e/ou resultados no país exportador e no país importador, sendo um assunto relevante para as administrações tributárias dos países onde essas operações ocorrem e para as empresas com unidades em mais de um país. O presente estudo apresenta uma análise relacionada aos Preços de Transferência praticados por uma empresa brasileira que importa matéria-prima de suas empresas vinculadas estabelecidas em outras jurisdições tributárias. É apresentado um estudo de caso descritivo que ilustra essa situação e as regras brasileiras de Preço de Transferência. Ao final, conclui-se que o contribuinte deve aplicar mais de uma metodologia de cálculo dentre as disponibilizadas pela legislação brasileira, a fim de identificar a que resulte em menor ajuste tributário. Conclui-se, adicionalmente, que a temática dos preços de transferência depende de muitas variáveis individuais, as quais devem ser estudadas e analisadas caso a caso, de acordo com as particularidades envolvidas em cada situação.
\end{abstract}

Palavras-Chave: Preços de Transferência; Preço Justo; Importação de Insumos; Empresas Vinculadas; Operações Intercompanhia.

\title{
CALCULATION METHODS FOR TRANSFER PRICING ON IMPORT OPERATIONS AND ITS IMPACTS ON TAX
}

\begin{abstract}
As the global economy continues to expand and markets become more open to investment, enterprises share activities among their units established in different countries. The prices determination for the transfer of goods between affiliated companies situated in different tax jurisdictions is called Transfer Pricing. For tax purposes, transfer pricing determines the amount of income that each party earns and thus, the amount of income tax due in both the export and import countries, representing a relevant issue to the tax administrations in countries where these operations occur and to the companies which have units in more than one country. This study presents an analysis related to Transfer Prices practiced by a Brazilian company that imports raw material from its associated units established in other tax jurisdictions. A case study that shows this situation and the Brazilian Transfer Pricing rules are presented. The conclusion is that the company should apply more than one of the available calculus methodologies in order to identify which one results in the lower tax adjustment. In addition to that, it is concluded that the Transfer Pricing is an issue that depends on many variables that should be carefully analyzed for each situation or company, considering the particularities of each situation.
\end{abstract}

Keywords: Transfer Pricing; Arm's Length (Fair Value); Raw Material Import; Associated Companies; Intercompany Transactions.

REAd - Edição 68, Volume 17, No 1, jan/abr 2011 - p. 270-297 